\title{
Acute remote ischemic preconditioning alleviates free radical injury and inflammatory response in cerebral ischemia/reperfusion rats
}

\author{
XIAN-LIANG MENG ${ }^{1}$, DONG-LIN ZHANG ${ }^{2}$ and SHI-HUA SUI ${ }^{3}$ \\ ${ }^{1}$ Department of Internal Neurology, Binzhou Central Hospital, Binzhou, Shandong 251700; \\ ${ }^{2}$ Department of Encephalopathy, Yangxin Hospital of Traditional Chinese Medicine, Binzhou, Shandong 251800; \\ ${ }^{3}$ Department of Internal Neurology, People's Hospital of Rizhao, Rizhao, Shandong 276826, P.R. China
}

Received January 19, 2018; Accepted August 31, 2018

DOI: $10.3892 /$ etm.2019.7797

\begin{abstract}
Remote ischemic preconditioning (IPreC) is an effective strategy to defend against cerebral ischemia/ reperfusion (IR) injury; however, its mechanisms remain to be elucidated. The aim of the present study was to investigate the effect of IPreC on brain tissue following cerebral ischemia, as well as the underlying mechanisms. Adult male Sprague-Dawley rats were treated with IPreC for $72 \mathrm{~h}$ prior to the induction of transient cerebral ischemia and reperfusion. The results demonstrated that IPreC reduced the area of cerebral infarction in the IR rats by 2,3,5-triphenyl-tetrazolium chloride staining. In addition, cell apoptosis was markedly suppressed by IPreC with an increased expression of B-cell lymphoma 2 (Bcl-2)/Bcl-2-associatd $\mathrm{X}$ protein using Terminal deoxynucleotidyl-transferase-mediated dUTP nick end labeling assay and western blot analysis. IR induced a decrease in the level of superoxide dismutase, and IPreC significantly suppressed increased levels of malondialdehyde, lactate dehydrogenase and nitric oxide. The expression of CD11b and CD18 was markedly inhibited by IpreC unsing flow cytometry. Furthermore, IPreC markedly decreased the release of pro-inflammatory factors interleukin (IL)-6 and IL- $1 \beta$, and enhanced the level of anti-inflammatory factors (IL-10 and IL-1 receptor antagonist) by ELISA assay. Finally, IPreC reduced the levels of transforming growth
\end{abstract}

Correspondence to: Dr Shi-Hua Sui, Department of Internal Neurology, People's Hospital of Rizhao, 126 Taian Road, Rizhao, Shandong 276826, P.R. China

E-mail: suishihua121@sina.com

Abbreviations: TAK1, transforming growth factor- $\beta$-activated kinase 1; Bcl-2, B-cell lymphoma 2; MDA, malondialdehyde; NO, nitric oxide; SOD, superoxide dismutase; LDH, lactate dehydrogenase

Key words: remote ischemic preconditioning, free radicals, inflammatory response, cerebral ischemia/reperfusion factor- $\beta$-activated kinase 1 , phosphorylated-P65/P65, and tumor necrosis factor- $\alpha$, indicating that the nuclear factor- $\kappa \mathrm{B}$ pathway was involved in $\mathrm{IPreC}$-mediated protection against cerebral ischemia. Taken together, the results suggested that IPreC decreased ischemic brain injury through alleviating free radical injury and the inflammatory response in cerebral IR rats.

\section{Introduction}

Ischemic stroke, a major cause of mortality and long-term disability among adults worldwide, often occurs when a cerebral blood vessel is ruptured or occluded, resulting in various acute and chronic diseases of the brain (1). Advances in medicine have led to the development of thrombolytic agents and intravascular techniques, which markedly decrease functional deficits $(2,3)$. Early reperfusion is crucial for the rapid recovery of cerebral blood flow in ischemic tissue, mainly involved in neuroprotection and thrombolysis. However, the re-establishment of blood flow following ischemia is always associated with certain side effects, which is termed ischemia/reperfusion (IR) injury (4). Continually, cerebral IR promotes the necrosis and apoptosis of nerve cells (5). Therefore, innovative treatment strategies are vital for defending the brain against IR injury to obtain a favorable prognosis.

Ischemic preconditioning (IPreC) was first described in 1986 in a canine myocardial ischemia model (6). IPreC means a brief ischemic event, which can mobilize intrinsic protective mechanisms that improve tolerance to severe ischemic insult (7). IPreC stands for an important adaptation of the central nervous system to sublethal ischemia, which is an effective method against IR injury through transient repeated ischemia $(8,9)$. Numerous studies have confirmed that IPreC improves ischemic tolerance in animal organs and tissues $(10,11)$. In previous years, orthopedic studies have focused on the protective effects of IPreC in IR injury of limb skeletal muscles $(12,13)$. According to the report of Dong et al (14), IPreC protected against IR injury in the rat sciatic nerve. However, the underlying mechanisms of IPreC resulting in neuronal protective effects remains to be fully elucidated. 
Accumulated evidence has confirmed that oxidative stress is implicated in the pathogenesis of ischemic and reperfusion injury in the brain $(15,16)$. Reports have indicated that oxidative burst lasted for several minutes upon the onset of reperfusion and persistently increased the production of oxygen radicals $(17,18)$. The overproduction of reactive oxygen species (ROS) results in oxidative damage, including lipid peroxidation, protein oxidation and DNA damage, which can lead to cell death (19). The brain is susceptible to the damage caused by oxidative stress and data support the hypothesis that oxidative stress is a potent mediator of cerebral IR injury $(20,21)$. Therefore, alleviating oxidative stress may be a major target for the treatment of cerebral IR.

Cerebral IR injury and its associated inflammation are vital in the evolution of brain injury (22). The activation of transcriptional regulatory factors can result in inflammatory responses, leading to the release of various pro-inflammatory factors (23). It has been reported that nuclear factor- $\mathrm{\kappa B}$ (NF- $\mathrm{kB}$ ) may be the 'main switch' of the neurovascular unit inflammatory reactions (24). It was found that the activation of NF- $\mathrm{KB}$ induced by transient ischemia occurs prior to DNA fragmentation (25). Several neuroprotective reagents exhibit the effect of suppressing the expression and/or activity of $\mathrm{NF}-\kappa \mathrm{B}$, suggesting that NF- $\kappa \mathrm{B}$ is important in regulating transient ischemia-induced neuronal death $(26,27)$. Therefore, the present study investigated the involvement of NF- $\mathrm{kB}$ in the effect of IPreC on cerebral IR injury.

In the present study, the effect of IPreC on cerebral IR injury and its underlying mechanisms were detected. The result demonstrated that IPreC mitigated cerebral IR injury via alleviating free radicals and the inflammatory response.

\section{Materials and methods}

Experimental animals. In total, 24 male Sprague-Dawley rats (age, 10-12 weeks; weight, 200-250 g) were obtained from the Experimental Animal Center of Binzhou Medical College (Binzhou, China). All experimental protocols were approved by the Animal Ethics Committee of Binzhou Medical College. All rats were fed in ventilated cages at $24^{\circ} \mathrm{C}$ and $30-50 \%$ humidity in a 12/12 h light/dark cycle, with free access to food and water for 1 week.

Induction of transient cerebral ischemia. Experiments were performed according to previous reports $(28,29)$. Briefly, each rat was placed in the supine position and its neck was incised in the middle ventral site to expose the left carotid artery. The left carotid artery was then isolated from the vagus nerve and clamped via small vascular clips to induce hypotension for $1 \mathrm{~h}$ by occlusion. A cerebral animal model was thus established. Subsequently, the rats were randomly divided into three groups $(\mathrm{n}=8)$; i) control group, healthy rats; ii) IR group, cerebral animal model treated with another $24 \mathrm{~h}$ reperfusion; iii) IR + IPreC group, rats were anesthetized with xylazine $(1.5 \mathrm{mg} / 100 \mathrm{~g})$ and ketamine $(4 \mathrm{mg} / 100 \mathrm{~g})$ by intramuscular injection, and then fixed on the operating table in a supine position. Following shaving and sterilization, a 3-4-cm-long cervical median incision was made. The left common carotid artery and the left external carotid artery were exposed, followed by three cycles of 10-min occlusion (left internal carotid artery was occluded using a microclamp) and $10 \mathrm{~min}$ of reperfusion (microclamp was removed to restore blood flow). Following IPreC for $72 \mathrm{~h}$, the rats were treated by the induction of transient cerebral IR (30). The rats were then sacrificed with an overdose of urethane for subsequent experiments.

Determination of cerebral infarction area. Following craniotomy, the brain was harvested and then stored at $-80^{\circ} \mathrm{C}$ for $15 \mathrm{~min}$. The brain tissues were cut into 2 -mm sections, and then stained with $2 \%$ 2,3,5-triphenyl-tetrazolium chloride (TTC) solution at $37^{\circ} \mathrm{C}$ for $30 \mathrm{~min}$ and soaked in $10 \%$ paraformaldehyde solution overnight. The areas of infarction were observed in gray under an inverted microscope. Image-Pro Plus 6.0 (Media Cybernetics Inc., Rockville, MD, USA) was used to measure the area of cerebral infarction.

Terminal deoxynucleotidyl-transferase-mediated dUTP nick end labeling (TUNEL) staining. Cryosections were cut (6- $\mu \mathrm{m}$-thick) and placed on slides. The measurement of apoptotic nuclei was accomplished by TUNEL in brain sections using an In-Situ Cell Death Detection kit (Roche Diagnostics $\mathrm{GmbH}$, Mannheim, Germany). Briefly, the sections were washed with PBS containing 1\% Triton-100 for $2 \mathrm{~min}$ on ice, and then incubated with $50 \mu 1$ TUNEL reaction mixture for $60 \mathrm{~min}$ at $37^{\circ} \mathrm{C}$. Subsequently, the sections were stained with DAPI. The TUNEL-positive nuclei were detected using a fluorescence microscope (Olympus Corporation, Tokyo, Japan).

Western blot assay. Tissue proteins were extracted from the brains and were homogenized in RIPA lysis buffer containing $1 \%$ PMSF on ice. The lysates were centrifuged at $10,000 \times \mathrm{g}$ for $15 \mathrm{~min}$ at $4^{\circ} \mathrm{C}$, and supernatant was collected. Total protein was quantified using a bicinchoninic acid assay (Solarbio Biotechnology Co., Ltd., Beijing, China) and $20 \mu \mathrm{g}$ protein/lane was separated via SDS-PAGE on a $10 \%$ gel. The separated proteins were transferred onto polyvinylidene difluoride membranes (EMD Millipore, Billerica, MA). Subsequently, the membranes were blocked with 5\% non-fat skim milk for $2 \mathrm{~h}$ at room temperature, followed by incubation at $4^{\circ} \mathrm{C}$ overnight with the following primary antibodies: B-cell lymphoma 2 (Bcl-2) (1:1,000; cat. no. 15071), Bcl-2-associated X protein (Bax) (1:1,000; cat. no. 5023), interleukin (IL)-1 $\beta$ (1:1,000; cat. no. 12703), IL-1 receptor antagonist (IL-1Ra) (1:1,000; cat. no. 3865), transforming growth factor- $\beta$-activated kinase 1 (TAK1; 1:1,000; cat. no. 5206), P65 (1:1,000; cat. no. 8242), phosphorylated (p-)P65 (1:1,000; cat. no. 3033), tumor necrosis factor (TNF)- $\alpha$ (1:1,000; cat. no. 6945) and GAPDH (1:1,000; cat. no. 5174; all Cell Signaling Technology, Inc., Danvers, MA, USA). Following washing with TBST twice, the membranes were incubated with horseradish peroxidase-conjugated secondary antibody anti-rabbit IgG (1:1,000; cat. no. 14708; CST) in TBST solution for $1 \mathrm{~h}$ at room temperature. Following washing, the signals of detected proteins were assessed using an enhanced chemiluminescence reaction system (EMD Millipore). ImageJ software (version 1.48; National Institutes of Health, Bethesda, MD, USA) was used to evaluate the protein levels.

Measurement of oxidative and anti-oxidative parameters in the brain. The brain tissues were homogenized in nine volumes of 
A

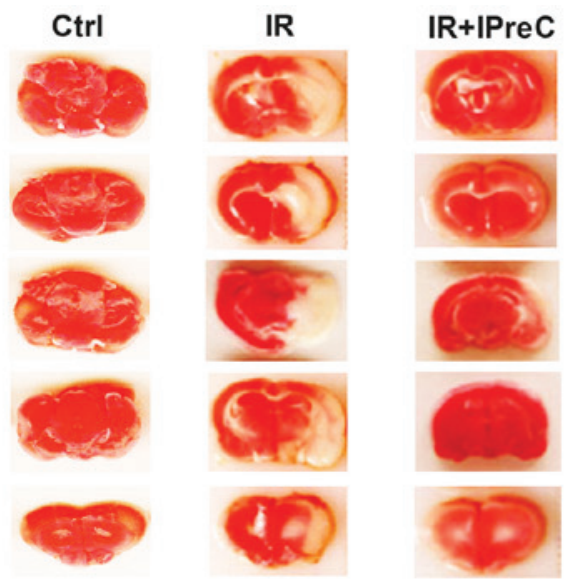

B

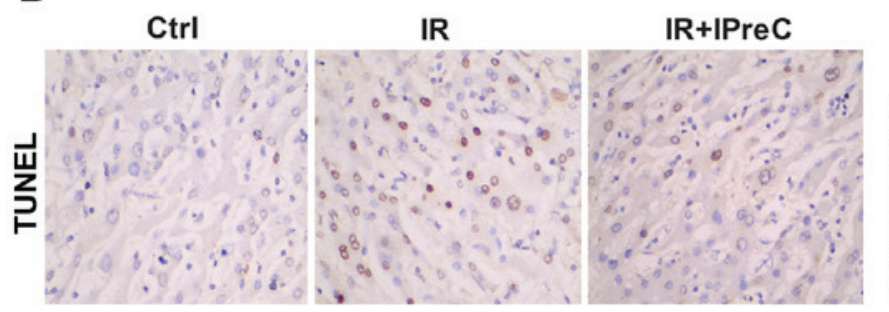

C

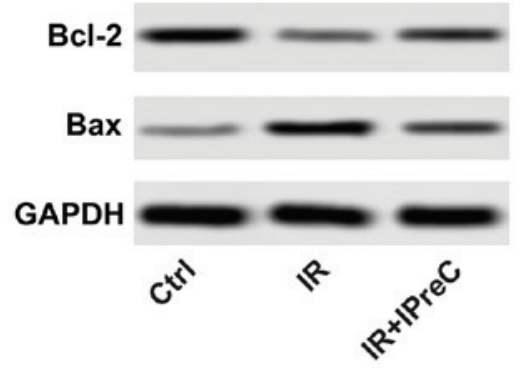

IR+IPreC

IR+IPreC

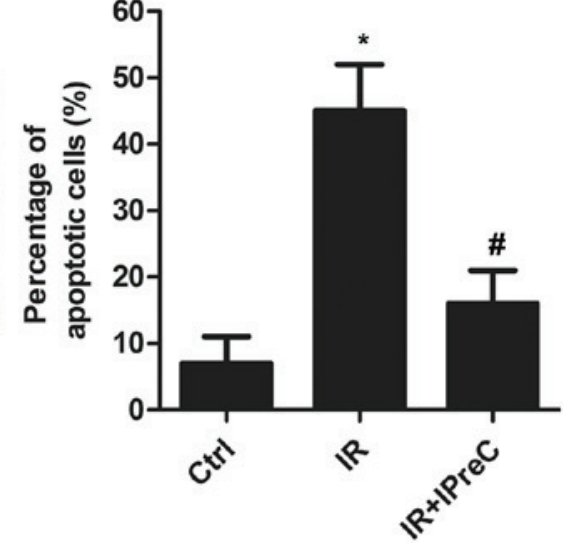

Figure 1. Remote IPreC alleviates cell apoptosis. (A) Cerebral infarction area was measured using 2,3,5-triphenyl-tetrazolium chloride staining. (B) Cell apoptosis was detected using TUNEL staining (magnification, 400x). The bar graph shows the statistical analysis of the percentage of apoptotic cells in the brain according to the result of the TUNEL assay. (C) Expression levels of Bcl-2 and Bax were detected using western blot analysis. Experiments were repeated at least three times, and error bars represent the mean \pm standard deviation $\left({ }^{*} \mathrm{P}<0.05\right.$, vs. Ctrl group; ${ }^{*} \mathrm{P}<0.05$, vs. IR group). IPreC, ischemic preconditioning; IR, ischemia/reperfusion; Ctrl, control; Bcl-2, B-cell lymphoma 2; Bax, Bcl-2-associated X protein.

ice-cold $0.9 \% \mathrm{NaCl}$ solution and centrifuged at $10,000 \mathrm{x}$ g for $10 \mathrm{~min}$ at $4^{\circ} \mathrm{C}$. The supernatant was collected for the measurement of oxidative stress parameters. Malondialdehyde (MDA), lactate dehydrogenase (LDH), nitric oxide (NO) and superoxide dismutase (SOD) levels in the brain were detected using corresponding biochemical methods according to the instructions of the reagent kits (Nanjing Jiancheng Bioengineering Institute, Nanjing, China).

Flow cytometry. Venous blood from the antecubital veins was collected in an EDTA-coated tube. Flow cytometry was performed within $4 \mathrm{~h}$ of blood sampling. Briefly, the red blood cells were lysed using $1 \%$ red blood cell lysis buffer (Nordic Biosite AB, Täby, Sweden). White blood cells $\left(5 \times 10^{5}\right)$ were collected in each test tube. The cells were then washed with an isotonic buffer (BD FACS Flow; BD Biosciences, Franklin Lakes, NJ, USA) and centrifuged at $600 \mathrm{xg}$ for $5 \mathrm{~min}$ at $4^{\circ} \mathrm{C}$. This process was repeated three times. Subsequently, cells were resuspended in the isotonic buffer, and monoclonal antibodies CD11b (1:1,000; ab8878) and CD18 (1:1,000; ab119830; both Abcam, Cambridge, UK ) were added to each sample and incubated in the dark at $4^{\circ} \mathrm{C}$ for $20 \mathrm{~min}$. The cells were then washed and resuspended in the isotonic FACS Flow buffer. The stained cells were detected using flow cytometry (BD FACSCanto II; BD Biosciences).

ELISA assay. The release of serum IL- 6 and IL-10 was measured using ELISA kits (Dakewe Biotech Co., Ltd., 

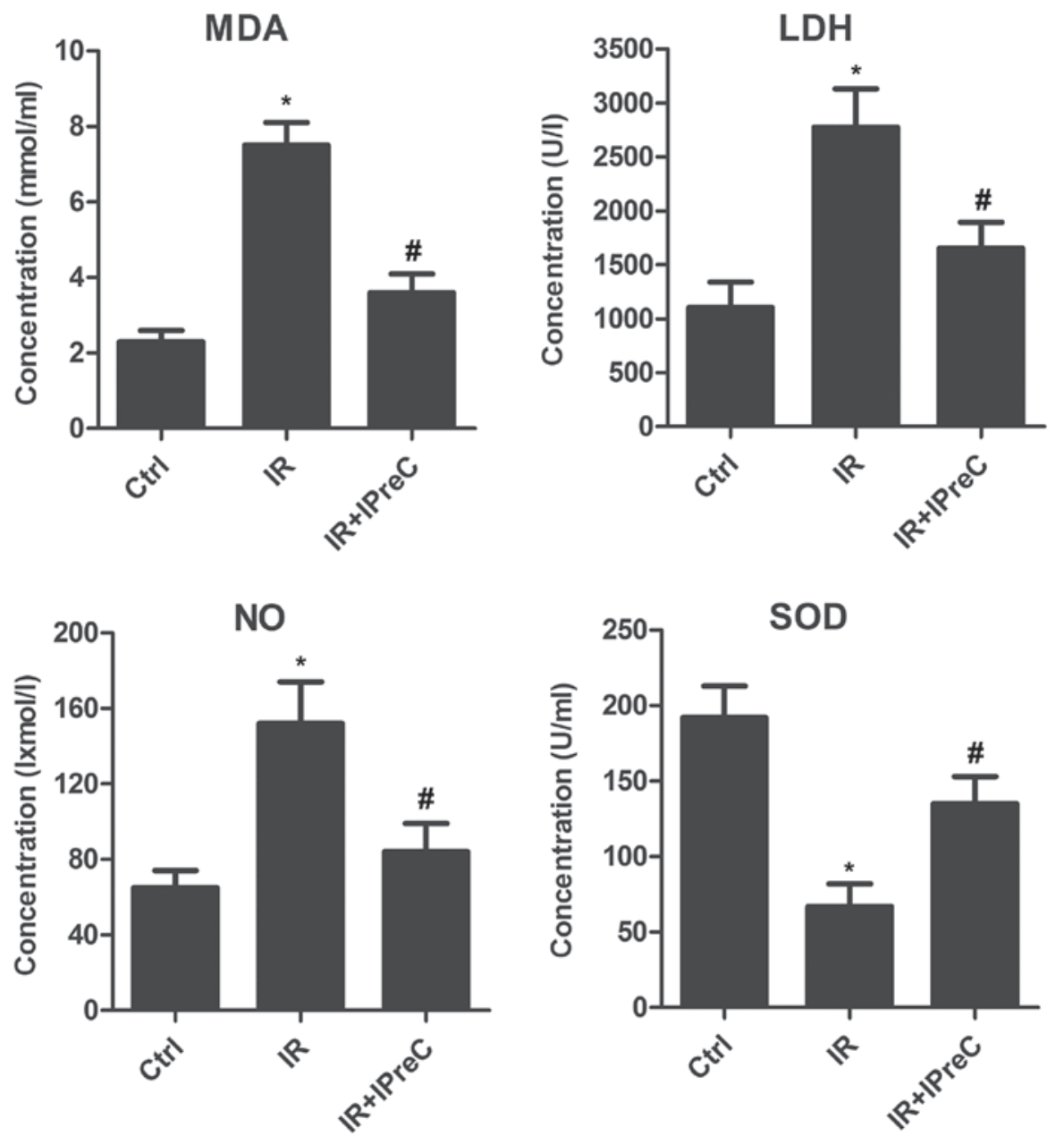

Figure 2. Remote IPreC attenuates free radical injury. The levels of MDA, LDH, NO and SOD were detected using corresponding biochemical methods. Experiments were repeated at least three times, and error bars represent the mean \pm standard deviation ( $\mathrm{P}<0.05$, vs. Ctrl group; ${ }^{\#} \mathrm{P}<0.05$ vs. IR group). IPreC, ischemic preconditioning; IR, ischemia/reperfusion; Ctrl, control; MDA, malondialdehyde; LDH, lactate dehydrogenase; NO, nitric oxide; SOD, superoxide dismutase.
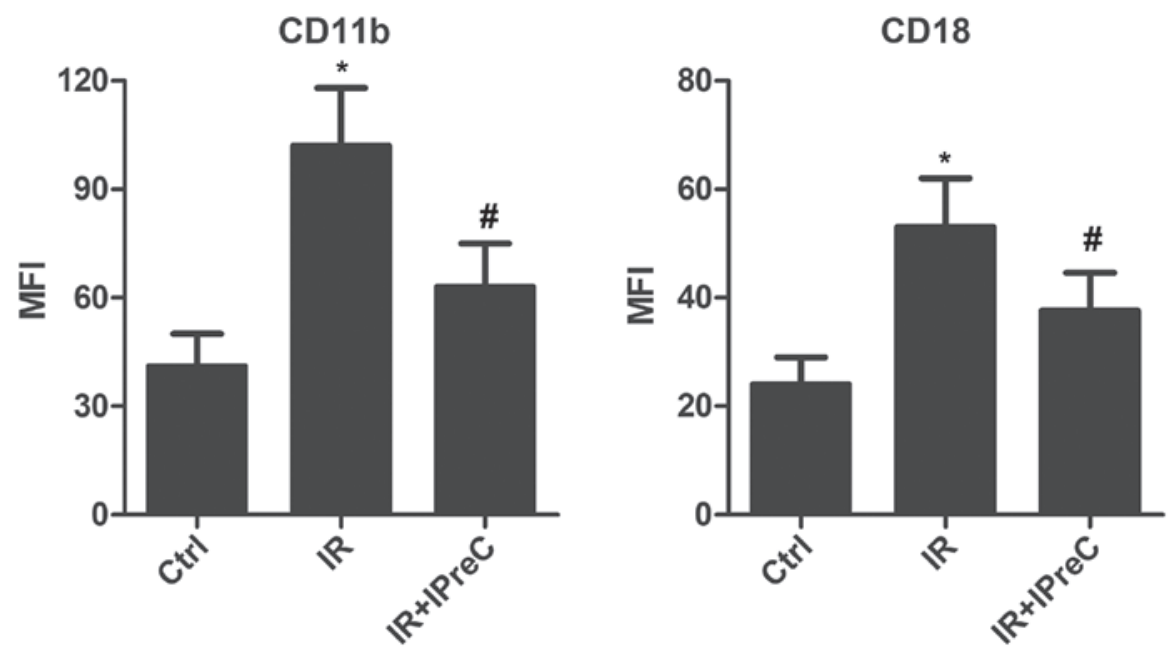

Figure 3. Remote IPreC decreases the levels of CD11b and CD18. The levels of CD11b and CD18 were detected using flow cytometry. Experiments were repeated at least three times, and error bars represent the mean \pm standard deviation $\left({ }^{*} \mathrm{P}<0.05\right.$, vs. Ctrl group; ${ }^{*} \mathrm{P}<0.05$, vs. IR group). IPreC, ischemic preconditioning; IR, ischemia/reperfusion; Ctrl, control; MFI, mean fluorescence intensity.

Shenzhen, China) according to the manufacturer's protocol. The reaction product was determined at $450 \mathrm{~nm}$ wavelength and the optical density values were detected and analyzed.
Statistical analysis. The results were analyzed using SPSS 17.0 software (SPSS, Inc., Chicago, IL, USA). The differences of the indicators between the three groups were compared by one-way 

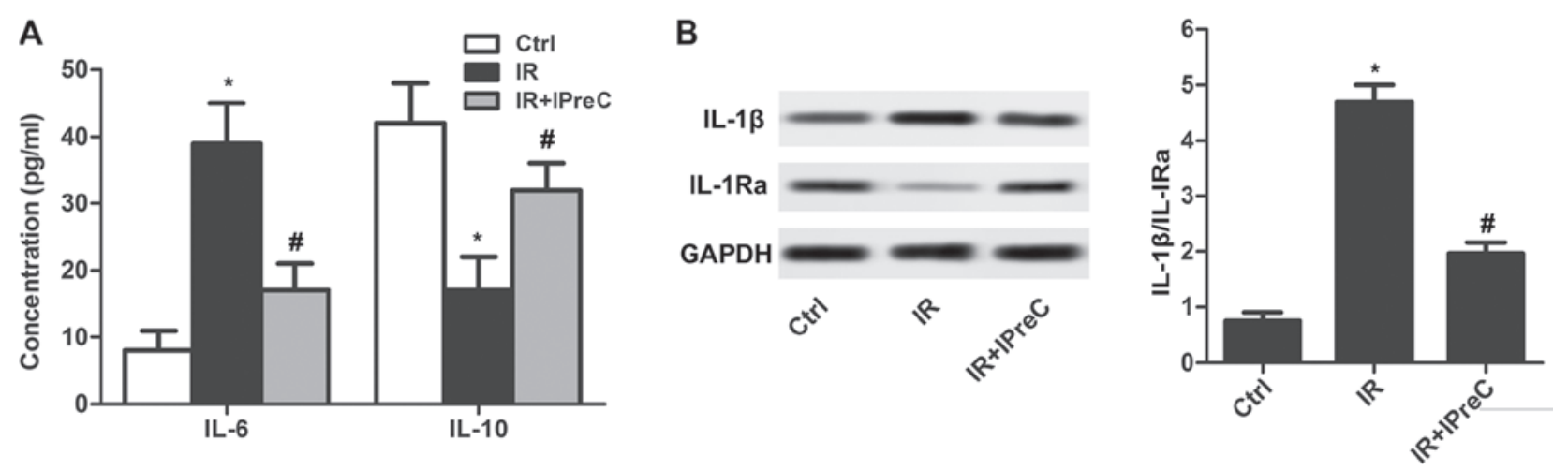

Figure 4. Remote IPreC ameliorates the inflammatory response. (A) Serum levels of IL-6 and IL-10 was detected using an ELISA assay. (B) Expression of IL-1Ra and IL-1 $\beta$ in the brain was measured using western blot analysis. Experiments were repeated at least three times, and error bars represent the mean \pm standard deviation ("P<0.05, vs. Ctrl group; ${ }^{~} \mathrm{P}<0.05$, vs. IR group). IPreC, ischemic preconditioning; IR, ischemia/reperfusion; Ctrl, control; IL, interleukin; IL-1Ra, IL-1 receptor antagonist.

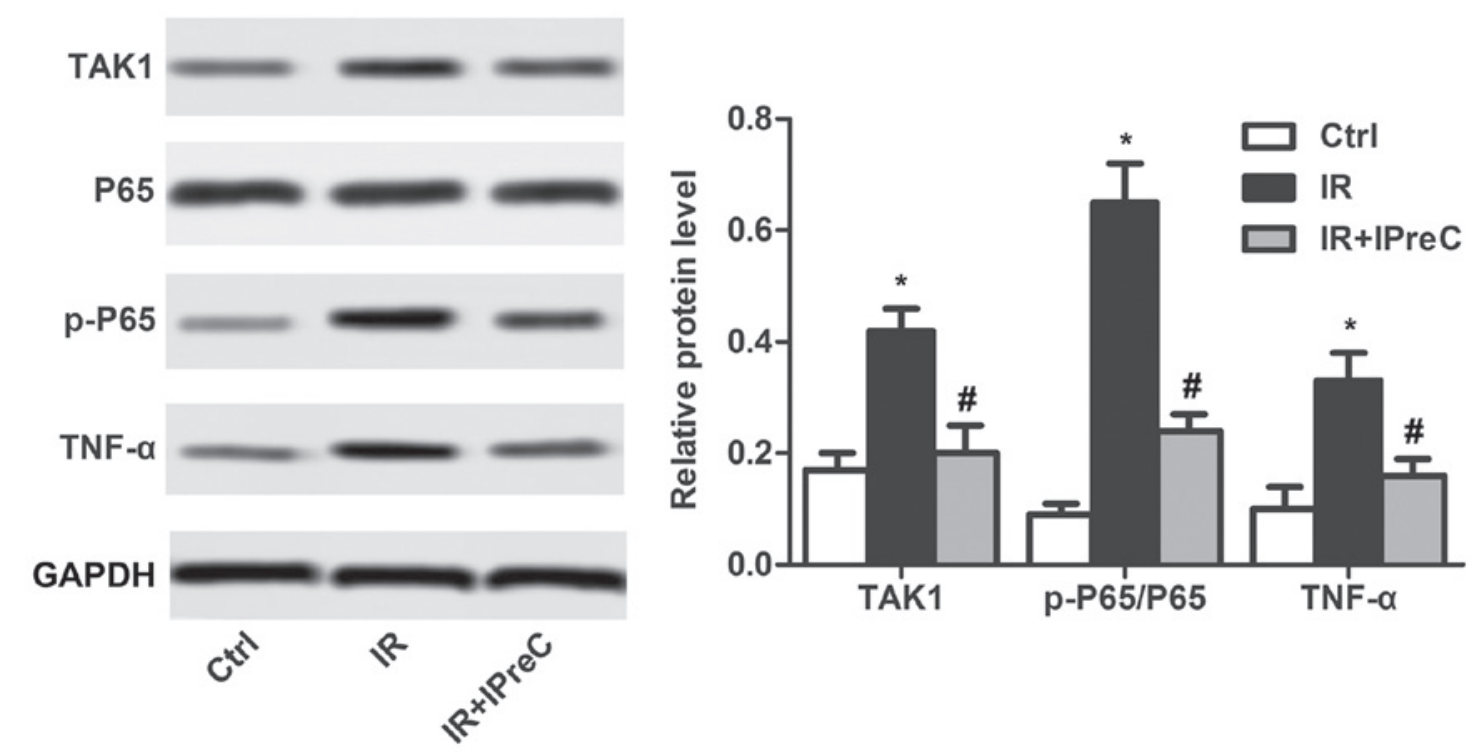

Figure 5. Remote IPreC inactivates the NF- $\mathrm{kB} / \mathrm{TAK} 1$ pathway. The expression levels of TAK1, P65, p-P65, and TNF- $\alpha$ were measured using western blot analysis. Experiments were repeated at least three times, and error bars represent the mean \pm standard deviation ( $\left({ }^{*}<0.05\right.$, vs. Ctrl group; ${ }^{*} \mathrm{P}<0.05$, vs. IR group)

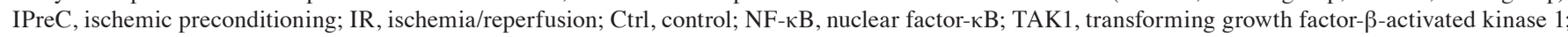
p-, phosphorylated; TNF- $\alpha$, tumor necrosis factor- $\alpha$.

analysis of variance followed by Boferroni's post hoc test. $\mathrm{P}<0.05$ was considered to indicate a statistically significant difference.

\section{Results}

IPreC alleviates cell apoptosis. To determine whether IPreC can mitigate cerebral IR injury, the area of cerebral infarction was detected using TTC staining. As illustrated in Fig. 1A, the increased area of cerebral infarction induced by IR was markedly suppressed by IPreC. In addition, IR-induced cell apoptosis was significantly inhibited by IPreC (Fig. 1B). The increased expression of $\mathrm{Bcl}-2 / \mathrm{Bax}$ in the IR + IPreC group compared with the IR group further validated this (Fig. 1C). These results indicated that IPreC ameliorated IR-induced cell apoptosis in the brain.

IPreC attenuates free radical injury. To investigate the association between the protective effect of IPreC on IR injury and its antioxidant status, relative expression levels of MDA, LDH, NO and SOD in brain tissue were measured using biochemical methods. As shown in Fig. 2, the IR rats exhibited a marked increase in MDA, LDH and NO content, whereas the expression of SOD was markedly suppressed, and these changes were reversed in IR + IPreC group. These results demonstrated the antioxidative stress effect of IPreC in mitigating cerebral IR-induced injury.

IPreC decreases the levels of CDIIb and CD18. To evaluate whether IPreC can affect the levels of the $\mathrm{CD} 11 \mathrm{~b}^{+}$and $\mathrm{CD} 18^{+}$ sub-population, flow cytometry and FACS were applied. The data indicated a marked elevation in the percentage of $\mathrm{CD} 11 \mathrm{~b}^{+}$ and $\mathrm{CD} 18^{+}$cells in the IR group compared with the control group. However, IPreC reversed these changes (Fig. 3).

IPreC ameliorates the inflammatory response. To detect the effect of IPreC on the IR-induced inflammatory response, 
inflammatory factors were measured. The results indicated that the serum level of IL- 6 was increased and that of IL-10 was decreased in the IR group compared with the control group. A reduced level of IL- 6 and elevated level of IL-10 was measured in the IR + IPreC group compared with the IR group (Fig. 4A). In addition, IPreC reduced the IR-induced increase in the ratio of IL-1 $\beta$ / IL-1Ra in the brain (Fig. 4B). These findings indicated that IPreC markedly suppressed the IR-induced inflammatory response.

IPreC inactivates the $N F-\kappa B$ pathway. To examine the mechanisms of IPreC on the IR-induced inflammatory reaction, the $\mathrm{NF}-\kappa \mathrm{B}$ pathway was detected using western blot analysis. As illustrated in Fig. 5, the increase in the expression levels of TAK1, p-P65/P65 and TNF- $\alpha$ induced by IR were be significantly suppressed by IPreC. These results demonstrated that

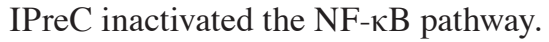

\section{Discussion}

Cerebral IR is the main cause of mortality and disability in adults leading to functional and structural injury in different brain regions (31). It is becoming increasingly accepted that IPreC is able to defend the brain against a subsequent longer ischemic insult and does not lead to neuronal death (8). IPreC exhibits a tolerance, which is termed 'ischemic tolerance' (32). However, the underlying molecular mechanisms of ischemic tolerance remained to be fully elucidated.

Apoptosis is involved in trauma, ischemia, and neurodegenerative diseases, thus being important in brain damage (33). The results demonstrated that many neurons in ischemic regions suffered from necrotic and apoptotic cell death (34). Studies have also indicated that Bcl-2 family proteins are involved in apoptotic signaling pathways (35). Bax is a pro-apoptotic member of the Bcl-2 family and is involved in inducing cell apoptosis (36). According to published reports, IPreC can alleviate IR injury via reducing apoptosis. For example, in IR-induced myocardial injury, IPreC markedly suppressed the expression of cleaved caspase 3, cleaved poly (ADP-ribose) polymerase and the Bax/Bcl-2 ratio (37). Jeong et al (38) demonstrated that IPreC increased the mRNA level of Bcl-2 in hepatic IR injury. In addition, it was reported that the decrease in the level of Bcl-2 and the increase in the level of Bax induced by IR were significantly suppressed by IPreC in renal IR injury (39). Similarly, in the present study, IPreC suppressed cell apoptosis with elevated Bcl-2/Bax level.

As byproducts or intermediates generated from complicated reactions in living cells, free radicals can lead to the production of nitrogen species and reactive oxygen (40). Under pathological circumstances, the excessive accumulation of free radicals and the deficiency of antioxidants result in tissue injury, namely oxidative damage (41). When lipids, protein and DNA are damaged by free radicals, stable oxidized biomolecule products, including MDA, are produced (42). Increasing evidence has indicated that IPreC is vital in alleviating oxidative damage following an IR event. Yang et al (43) demonstrated that IPreC reduced the level of MDA and elevated the activity of SOD in serum and the intestine following an intestinal IR event. In addition, IPreC decreased the level of NO in the plasma of mice suffering a kidney IR event (44). The serum level of LDH was reported to be significantly lower under IPreC treatment in patients with IR injury following tourniquet release during total knee arthroplasty (45). Similarly, in the present study, IR significantly downregulated the level of SOD and increased the levels of MDA, LDH and NO. However, IPreC reversed these changes.

A previous study indicated that oxygen free radicals can also be triggered by infiltrating leukocytes following reperfusion (46). According to previous reports, IR triggers microcirculation interplay in various ways that promote the expression of leukocyte adhesion molecules CD11b/CD18, promoting the adhesion of leukocytes to venules (47). The leukocytes adhere to the venular wall and, in turn, release peroxides and protease that cause the leakage of serum $(48,49)$. Therefore, the expression levels of CD11b and CD18 are directly associated with the extent of post-operative IR injury $(50,51)$. Kharbanda et al (52) reported that IPreC inhibited the increased expression of neutrophil CD11b in humans with forearm ischemia followed by reperfusion. Chouker et al (51) demonstrated that the expression of CD18 did not elevate further by IPreC in patients subjected to IR injury. The present study was in accordance with these results. IPreC, significantly suppressed the increased CD11b and CD18 expression levels induced by IR.

The IR injury in organs is caused by various factors, including inflammation. During the inflammatory reaction, pro-inflammatory factors, including IL- 6 and IL-1 $\beta$, were released, and the level of anti-inflammatory cytokines (IL-10 and IL-1Ra) was decreased (53). Previous studies have indicated that IPreC markedly suppressed the gene expression level of pro-inflammatory factors (TNF- $\alpha$, IL-1 $\beta$, and IL-6) and chemokines in patients with renal IR injury (54). In addition, IPreC inhibited the release of IL-1 $\beta$ and enhanced the generation of IL-10 following IR in normal and steatotic livers (55). IPreC also led to inhibition of the mRNA and protein levels of IL-1 $\beta$ at $6 \mathrm{~h}$ and the increased the protein level of IL-1Ra at $24 \mathrm{~h}$ (56). Similarly, in the present study, IPreC suppressed the increased IL- 6 and IL-1 $\beta$ and decreased IL-10 and IL-1Ra expression levels induced by IR.

TAK1 is an emerging therapeutic target for inflammation and fibrosis and the convergence point in cellular responses to inflammatory stimuli, modulating the expression of mediators and cell death (57). The downregulation of TAK1 has been reported to ameliorate IR injury-induced renal interstitial fibrosis in mice (58). By contrast, the pathogenesis of IR injury is involved in tissue hypoxia, reactive oxygen species, complement activation, and the activity of pro- and anti-apoptotic signaling cascades, all of which are controlled at a certain level through the activity of the NF- $\kappa \mathrm{B}$ pathway (59). NF- $\kappa \mathrm{B}$ promotes the release of a host of inflammatory cytokines and cytotoxins, including TNF- $\alpha$ and IL-1 $\beta$ (60). The mitogen-activated protein kinase family member TAK1 is involved in the mechanism of hypoxia-induced NF- $\kappa \mathrm{B}(61)$. It has been suggested and supported by studies that IPreC can inactivate the $\mathrm{NF}-\kappa \mathrm{B}$ pathway in IR injury. For example, combining IPreC with sevoflurane postconditioning protected rats against myocardial injury induced by IR partly via inactivating the toll-like receptor 4/myeloid differentiation primary response 88/NF- $\mathrm{B}$ signaling pathway (37). IPreC markedly alleviated lipopolysaccharide-induced liver injury via the inhibition of 
$\mathrm{NF}-\kappa \mathrm{B}$ activation in mice (62). Similarly, in the present study, IPreC significantly suppressed IR-induced increased levels of TAK1, p-P65/P65 and TNF- $\alpha$.

Taken together, the results of the present study suggested that cerebral IR injury may be ameliorated by IPreC via decreasing free radicals and the inflammatory response. These results may provide novel insight into the mechanisms of IPreC for the treatment of cerebral IR injury.

\section{Acknowledgements}

The authors would like to thank Dr Xian-Liang Meng (Binzhou Central Hospital, Binzhou, China) for providing technical support for the present study.

\section{Funding}

No funding was received.

\section{Availability of data and materials}

The datasets used and/or analyzed in the present study are available from the corresponding author on reasonable request.

\section{Authors' contributions}

XLM and DLZ obtained the data regarding the IR injury model establishment and IPreC. DLZ performed the ELISA assay and statistical analysis. SHS designed the study and prepared the manuscript. All authors read and approved the final manuscript.

\section{Ethics approval and consent to participate}

All experimental protocols in the present study were approved by the Animal Ethics Committee of Binzhou Medical College (Binzhou, China). All experiments were performed in compliance with relevant laws and guidelines. All experiments were performed according to the institutional guidelines of Binzhou Central Hospital.

\section{Patient consent for publication}

Not applicable.

\section{Competing interests}

The authors declare that they have no competing interests.

\section{References}

1. Mestriner RG, Saur L, Bagatini PB, Baptista PP, Vaz SP, Ferreira K, Machado SA, Xavier LL and Netto CA: Astrocyte morphology after ischemic and hemorrhagic experimental stroke has no influence on the different recovery patterns. Behav Brain Res 278: 257-261, 2015.

2. Gomis M and Davalos A: Recanalization and reperfusion therapies of acute ischemic stroke: What have we learned, what are the major research questions, and where are we headed? Front Neurol 5: 226, 2014

3. Fjetland L and Roy S: Transcarotid endovascular thrombectomy for acute ischemic stroke. J Vasc Int Radiol 29: 1006-1010, 2018.
4. Chouchani ET, Pell VR, Gaude E, Aksentijević D, Sundier SY, Robb EL, Logan A, Nadtochiy SM, Ord ENJ, Smith AC, et al: Ischaemic accumulation of succinate controls reperfusion injury through mitochondrial ROS. Nature 515: 431-435, 2014.

5. Hu YQ, Chen W, Yan MH, Lai JJ, Tang N and Wu L: Ischemic preconditioning protects brain from ischemia/reperfusion injury by attenuating endoplasmic reticulum stress-induced apoptosis through PERK pathway. Eur Rev Med Pharmacol Sci 21: 5736-5744, 2017.

6. Murry CE, Jennings RB and Reimer KA: Preconditioning with ischemia: A delay of lethal cell injury in ischemic myocardium. Circulation 74: 1124-1136, 1986.

7. Wegener S, Gottschalk B, Jovanovic V, Knab R, Fiebach JB, Schellinger PD, Kucinski T, Jungehülsing GJ, Brunecker P, Müller B, et al: Transient ischemic attacks before ischemic stroke: Preconditioning the human brain? A multicenter magnetic resonance imaging study. Stroke 35: 616-621, 2004.

8. Lehotsky J, Burda J, Danielisova V, Gottlieb M, Kaplan P and Saniova B: Ischemic tolerance: The mechanisms of neuroprotective strategy. Anat Rec (Hoboken) 292: 2002-2012, 2009.

9. Hess DC, Hoda MN and Bhatia K: Remote limb perconditioning [corrected] and postconditioning: Will it translate into a promising treatment for acute stroke? Stroke 44: 1191-1197, 2013.

10. Thompson JW, Dave KR, Young JI and Perez-Pinzon MA: Ischemic preconditioning alters the epigenetic profile of the brain from ischemic intolerance to ischemic tolerance. Neurotherapeutics 10: 789-797, 2013.

11. Yunoki M, Kanda T, Suzuki K, Uneda A, Hirashita K and Yoshino K: Ischemic tolerance of the brain and spinal cord: A review. Neurol Med Chir (Tokyo) 57: 590-600, 2017.

12. Schoen M, Rotter R, Gierer P, Gradl G, Strauss U, Jonas L, Mittlmeier T and Vollmar B: Ischemic preconditioning prevents skeletal muscle tissue injury, but not nerve lesion upon tourniquet-induced ischemia. J Trauma 63: 788-797, 2007.

13. Jeffries O, Waldron M, Pattison JR and Patterson SD: Enhanced local skeletal muscle oxidative capacity and microvascular blood flow following 7-day ischemic preconditioning in healthy humans. Front Physiol 9: 463, 2018.

14. Dong S, Cao Y, Li H, Tian J, Yi C and Sang W: Impact of ischemic preconditioning on ischemia-reperfusion injury of the rat sciatic nerve. Int J Clin Exp Med 8: 16245-16251, 2015.

15. Granger DN and Kvietys PR: Reperfusion injury and reactive oxygen species: The evolution of a concept. Redox Biol 6: 524-551, 2015.

16. Wanchao S, Chen M, Zhiguo S, Futang X and Mengmeng S: Protective effect and mechanism of Lactobacillus on cerebral ischemia reperfusion injury in rats. Braz J Med Biol Res 51: e7172, 2018.

17. Valko M, Leibfritz D, Moncol J, Cronin MT, Mazur M and Telser J: Free radicals and antioxidants in normal physiological functions and human disease. Int J Biochem Cell Biol 39: 44-84, 2007.

18. Matsuda S, Umeda M, Uchida H, Kato H and Araki T: Alterations of oxidative stress markers and apoptosis markers in the striatum after transient focal cerebral ischemia in rats. J Neural Transm (Vienna) 116: 395-404, 2009

19. Angelova PR and Abramov AY: Role of mitochondrial ROS in the brain: From physiology to neurodegeneration. FEBS Lett 592: 692-702, 2018.

20. Yao Y, Chen L, Xiao J, Wang C, Jiang W, Zhang R and Hao J: Chrysin protects against focal cerebral ischemia/reperfusion injury in mice through attenuation of oxidative stress and inflammation. Int J Mol Sci 15: 20913-20926, 2014.

21. Singh V, Krishan P and Shri R: Antioxidant-mediated neuroprotection by allium schoenoprasum $\mathrm{L}$. leaf extract against ischemia reperfusion-induced cerebral injury in mice. J Basic Clin Physiol Pharmacol 29: 403-410, 2018.

22. Bohacek I, Cordeau P, Lalancette-Hebert M, Gorup D, Weng YC, Gajovic S and Kriz J: Toll-like receptor 2 deficiency leads to delayed exacerbation of ischemic injury. J Neuroinflammation 9: 191, 2012.

23. Chapman SN, Mehndiratta P, Johansen MC, McMurry TL, Johnston KC and Southerland AM: Current perspectives on the use of intravenous recombinant tissue plasminogen activator (tPA) for treatment of acute ischemic stroke. Vasc Health Risk Manag 10: 75-87, 2014.

24. del Zoppo GJ: Acute anti-inflammatory approaches to ischemic stroke. Ann N Y Acad Sci 1207: 143-148, 2010.

25. Clemens JA, Stephenson DT, Dixon EP, Smalstig EB, Mincy RE, Rash KS and Little SP: Global cerebral ischemia activates nuclear factor-kappa B prior to evidence of DNA fragmentation. Brain Res Mol Brain Res 48: 187-196, 1997. 
26. Subedi L, Venkatesan R and Kim SY: Neuroprotective and anti-inflammatory activities of allyl isothiocyanate through attenuation of JNK/NF- $\mathrm{KB} / \mathrm{TNF}-\alpha$ signaling. Int J Mol Sci 18 : E1423, 2017.

27. Wang L, Zhang Y, Asakawa T, Li W, Han S, Li Q, Xiao B, Namba H, Lu C and Dong Q: Neuroprotective effect of neuroserpin in oxygen-glucose deprivation- and reoxygenation-treated rat astrocytes in vitro. PLoS One 10: e0123932, 2015.

28. Giacoppo S, Galuppo M, Iori R, De Nicola GR, Bramanti P and Mazzon E: (RS)-glucoraphanin purified from tuscan black kale and bioactivated with myrosinase enzyme protects against cerebral ischemia/reperfusion injury in rats. Fitoterapia 99: 166-177, 2014.

29. Awooda HA, Lutfi MF, Sharara GM and Saeed AM: Role of $\mathrm{N}$-Nitro-L-Arginine-Methylester as anti-oxidant in transient cerebral ischemia and reperfusion in rats. Exp Transl Stroke Med 5: 1, 2013.

30. Altintas O, Antar V, Baran O, Karatas E, Altintas MO, Kesgin S, Buyukpinarbasili N, Kocyigit A and Asil T: Neuroprotective effects of hemicraniectomy in malign middle cerebral artery infarctions: Experimental study. J Neurosurg Sci, 2015.

31. Qi D, Liu H, Niu J, Fan X, Wen X, Du Y, Mou J, Pei D, Liu Z, Zong Z, et al: Heat shock protein 72 inhibits c-Jun N-terminal kinase 3 signaling pathway via Akt1 during cerebral ischemia. J Neurol Sci 317: 123-129, 2012.

32. Feng Z, Davis DP, Sasik R, Patel HH, Drummond JC and Patel PM: Pathway and gene ontology based analysis of gene expression in a rat model of cerebral ischemic tolerance. Brain Res 1177: 103-123, 2007.

33. Friedlander RM: Apoptosis and caspases in neurodegenerative diseases. N Engl J Med 348: 1365-1375, 2003.

34. Dziodzio T, Biebl M and Pratschke J: Impact of brain death on ischemia/reperfusion injury in liver transplantation. Curr Opin Organ Transplant 19: 108-114, 2014

35. Youle RJ and Strasser A: The BCL-2 protein family: Opposing activities that mediate cell death. Nat Rev Mol Cell Biol 9: 47-59, 2008.

36. Kale J, Osterlund EJ and Andrews DW: BCL-2 family proteins: Changing partners in the dance towards death. Cell Death Differ 25: 65-80, 2018.

37. Zhang J, Yu P, Chen M, Peng Q, Wang Z and Dong $\mathrm{N}$ : Remote ischaemic preconditioning and sevoflurane postconditioning synergistically protect rats from myocardial injury induced by ischemia and reperfusion partly via inhibition TLR4/MyD88/NF- $\kappa \mathrm{B}$ signaling pathway. Cell Physiol Biochem 41: 22-32, 2017

38. Jeong JS, Kim D, Kim KY, Ryu S, Han S, Shin BS, Kim GS, Gwak MS and Ko JS: Ischemic preconditioning produces comparable protection against hepatic ischemia/reperfusion injury under isoflurane and sevoflurane anesthesia in rats. Transplant Proc 49: 2188-2193, 2017.

39. Shen S, Zhou J, Meng S, Wu J, Ma J, Zhu C, Deng G and Liu D: The protective effects of ischemic preconditioning on rats with renal ischemia-reperfusion injury and the effects on the expression of Bcl-2 and Bax. Exp Ther Med 14: 4077-4082, 2017.

40. Ray PD, Huang BW and Tsuji Y: Reactive oxygen species (ROS) homeostasis and redox regulation in cellular signaling. Cell Signal 24: 981-990, 2012

41. Tothova L and Celec P: Oxidative stress and antioxidants in the diagnosis and therapy of periodontitis. Front Physiol 8: 1055, 2017.

42. Flatow J, Buckley P and Miller BJ: Meta-analysis of oxidative stress in schizophrenia. Biol Psychiatry 74: 400-409, 2013.

43. Yang B, Chen Y, Long YH, Fan X, Liu KX, Wang XB and Zhou J: Intestinal and limb ischemic preconditioning provides a combined protective effect in the late phase, but not in the early phase, against intestinal injury induced by intestinal ischemia-reperfusion in rats. Shock 49: 596-603, 2018.

44. Tuorkey MJ: Kidney remote ischemic preconditioning as a novel strategy to explore the accurate protective mechanisms underlying remote ischemic preconditioning. Interv Med Appl Sci 9: 20-26, 2017.

45. Oh CS, Kim SH, Lee J and Rhee KY: Impact of remote ischaemic preconditioning on cerebral oxygenation during total knee arthroplasty. Int J Med Sci 14: 115-122, 2017.
46. Stoll G, Jander S and Schroeter M: Inflammation and glial responses in ischemic brain lesions. Prog Neurobiol 56: 149-171, 1998.

47. Lan W, Harmon D, Wang JH, Ghori K, Shorten G and Redmond P: The effect of lidocaine on in vitro neutrophil and endothelial adhesion molecule expression induced by plasma obtained during tourniquet-induced ischaemia and reperfusion. Eur J Anaesthesiol 21: 892-897, 2004.

48. Han JY, Miura S, Akiba Y, Higuchi H, Kato S, Suzuki H, Yokoyama $\mathrm{H}$ and Ishii $\mathrm{H}$ : Chronic ethanol consumption exacerbates microcirculatory damage in rat mesentery after reperfusion. Am J Physiol Gastrointest Liver Physiol 280: G939-G948, 2001.

49. Dehnadi A, Benedict Cosimi A, Neal Smith R, Li X, Alonso JL, Means TK and Arnaout MA: Prophylactic orthosteric inhibition of leukocyte integrin CD11b/CD18 prevents long-term fibrotic kidney failure in cynomolgus monkeys. Nat Commun 8: 13899 , 2017.

50. Healy DG, Wood AE, O'Neill A, McCarthy JF, Fitzpatrick JM and Watson RW: Can preoperative modelling of individual neutrophil adhesion responses predict renal morbidity? Eur J Cardiothorac Surg 31: 1088-1093, 2007.

51. Chouker A, Martignoni A, Schauer R, Dugas M, Rau HG, Jauch KW, Peter K and Thiel M: Beneficial effects of ischemic preconditioning in patients undergoing hepatectomy: The role of neutrophils. Arch Surg 140: 129-136, 2005.

52. Kharbanda RK, Peters M, Walton B, Kattenhorn M, Mullen M, Klein N, Vallance P, Deanfield J and MacAllister R: Ischemic preconditioning prevents endothelial injury and systemic neutrophil activation during ischemia-reperfusion in humans in vivo. Circulation 103: 1624-1630, 2001.

53. Halladin NL, Ekelof S, Alamili M, Bendtzen K, Lykkesfeldt J, Rosenberg J and Gögenur I: Lower limb ischaemia and reperfusion injury in healthy volunteers measured by oxidative and inflammatory biomarkers. Perfusion 30: 64-70, 2015.

54. Choi HS, Hwang JK, Kim JG, Hwang HS, Lee SJ, Chang YK, Kim JI and Moon IS: The optimal duration of ischemic preconditioning for renal ischemia-reperfusion injury in mice. Ann Surg Treat Res 93: 209-216, 2017.

55. Serafin A, Rosello-Catafau J, Prats N, Gelpi E, Rodes J and Peralta C: Ischemic preconditioning affects interleukin release in fatty livers of rats undergoing ischemia/reperfusion. Hepatology 39: 688-698, 2004.

56. Shin JA, Park EM, Choi JS, Seo SM, Kang JL, Lee KE and Cho S: Ischemic preconditioning-induced neuroprotection is associated with differential expression of IL-1beta and IL-1 receptor antagonist in the ischemic cortex. J Neuroimmunol 217: 14-19, 2009.

57. Kilty I and Jones LH: TAK1 selective inhibition: State of the art and future opportunities. Future Med Chem 7: 23-33, 2015.

58. Wu H, Zhou J, Ou W, Li Y, Liu M and Yang C: TAK1 as the mediator in the protective effect of propofol on renal interstitial fibrosis induced by ischemia/reperfusion injury. Eur J Pharmacol 811: 134-140, 2017.

59. Latanich CA and Toledo-Pereyra LH: Searching for NF-kappaB-based treatments of ischemia reperfusion injury. J Invest Surg 22: 301-315, 2009.

60. Morishita R, Sugimoto T, Aoki M,Kida I, Tomita N, Moriguchi A, Maeda K, Sawa Y, Kaneda Y, Higaki J and Ogihara T: In vivo transfection of cis element 'decoy' against nuclear factor-kappaB binding site prevents myocardial infarction. Nat Med 3: 894-899, 1997.

61. Bandarra D, Biddlestone J, Mudie S, Muller HA and Rocha S: Hypoxia activates IKK-NF-kappaB and the immune response in Drosophila melanogaster. Biosci Rep 34: e00127, 2014.

62. Shin HJ, Won NH and Lee HW: Remote ischemic preconditioning prevents lipopolysaccharide-induced liver injury through inhibition of NF-kappaB activation in mice. J Anesth 28: 898-905, 2014.

This work is licensed under a Creative Commons Attribution-NonCommercial-NoDerivatives 4.0 International (CC BY-NC-ND 4.0) License. 